\title{
Patient satisfaction with cardiac rehabilitation: association with utilization, functional capacity, and heart-health behaviors [Corrigendum]
}

\author{
Ali S, Chessex C, Bassett-Gunter R, Grace SL. Patient Prefer \\ Adherence. 2017;11:821-830.
}

Page 824, Heart-health behaviors section, third paragraph, the text "Finally, the 4-item version of Morisky Medication Adherence Scale ${ }^{34}$ was also administered. Response options are "yes" I agree with the statement (scored as 0) or "no" I do not (scored as 1). Responses are summed, and a total score of $<4$ indicates "non-adherence" should have read "Finally, the 4-item version of Morisky Medication Adherence Scale ${ }^{34}$ was also administered".

Page 825, Column 1, second paragraph, the text "As shown in Figure 1, less than half of participants completed the 2-year follow-up survey. Table 1 lists the pre-CR characteristics of participants retained 2 years later versus those lost to follow-up. With regard to sociodemographic characteristics, as shown, retained participants were more likely to self-report "North American" ethnocultural background versus any other origin (eg, European, Asian) compared to those lost to follow-up. With regard to clinical characteristics, retained participants were significantly more likely to have been referred to $\mathrm{CR}$ for an indication other than revascularization compared to those lost to follow-up. No other differences were observed" should have read "As shown in Figure 1, less than half of participants completed the 2-year follow-up survey. Table 1 lists the pre-CR characteristics of participants retained 2 years later versus those lost to follow-up. With regard to sociodemographic characteristics, as shown, retained participants were more likely to self-report "North American" ethnocultural background versus any other origin (eg, European, Asian) compared to those lost to follow-up. No other differences were observed".

Page 826, Table 2, the $\mathrm{n}(\%)$ for Completion under CR utilization (discharge), the data "209 (60.2\%)" should have read " $247(60.2 \%)$ ".

Page 826, Table 2, Notes section, the text "Independent samples $t$-test. ${ }^{\ddagger}$ Analysis of variance. ${ }^{¥}$ Adjusted for sex" should have read "Independent samples $t$-test. ${ }^{£}$ Analysis of variance. ${ }^{¥}$ Adjusted for sex. MMAS-4 is protected by US and International Trademark and Copyright laws. Permission for use is required. A license agreement is available from: MMAS Research LLC 14725 NE 20th St Bellevue WA 98007".

Page 829, Acknowledgment, the text "The authors acknowledge Terry Fair, BEd, Cynthia Parson, BSc, PT, RPT, and Ann Briggs, BSc, PT, RPT, for facilitating patient recruitment" should have read "The authors acknowledge Terry Fair, BEd, Cynthia Parson, BSc, PT, RPT, and Ann Briggs, $\mathrm{BSc}, \mathrm{PT}$, RPT, for facilitating patient recruitment. MMAS-4 is protected by US and International Trademark and Copyright laws. Permission for use is required. A license agreement is available from: MMAS Research LLC $14725 \mathrm{NE}$ 20th St Bellevue WA 98007”.

Page 830, Reference 34 is incorrect the correct reference is "Morisky DE, DiMatteo MR. Improving the measurement of self-reported medication nonadherence: Response to Authors. J Clin Epidemiol. 2011;64:255-263”.
Patient Preference and Adherence

\section{Publish your work in this journal}

Patient Preference and Adherence is an international, peer-reviewed, open access journal that focuses on the growing importance of patient preference and adherence throughout the therapeutic continuum. Patient satisfaction, acceptability, quality of life, compliance, persistence and their role in developing new therapeutic modalities and compounds to optimize

\section{Dovepress}

clinical outcomes for existing disease states are major areas of interest for the journal. This journal has been accepted for indexing on PubMed Central. The manuscript management system is completely online and includes a very quick and fair peer-review system, which is all easy to use. Visit http://www. dovepress.com/testimonials.php to read real quotes from published authors. 